\title{
Genetic Parameter Analysis of Indicator Traits of Gastrointestinal Nematode Infection in Sheep Breeds
}

\author{
R. Selvam $\times \mathbb{0}$ \\ Livestock Farm Complex, Veterinary College and Research Institute, Tirunelveli, Tamil Nadu (627 358), India
}

Open Access

Corresponding $邓$ selvam.r@tanuvas.ac.in

0000-0002-1021-4411

\section{ABSTRACT}

$\mathrm{T}$

his study was undertaken with an aim to analyse the indicator traits of gastrointestinal nematode infection viz.,

FAMACHA score, FEC and PCV and to estimate the correlation among these traits. This study was carried out in a total of 100 sheep, 50 of each Kilakarsal and Vembur sheep breeds. The data were analysed using a mixed model least-squares analysis for fitting constants and the relationship among traits were estimated. The overall least-squares mean for FAMACHA scores were $2.88 \pm 1.144$ and $2.9 \pm 0.151$; FEC were $792 \pm 121.448$ and $767.0 \pm 100.576$; PCV were $26.38 \pm 0.199$ and $26.14 \pm 0.189$, in Kilakarsal and Vembur sheep, respectively. The Pearson Correlations study revealed that there is highly significant $(\mathrm{P}<0.01)$ positive correlation between FAMACHA scores and FEC in Kilakarsal $\left(0.835^{* *}\right)$ and Vembur $\left(0.863^{* *}\right)$ sheep, But PCV is highly significantly negatively correlated with FAMACHA scores (Kilakarsal: $-0.843^{* *}$ and Vembur: $-0.883^{* *}$ ) and FEC (Kilakarsal: $-0.874^{*}$ and Vembur: $\left.-0.924^{*}\right)$. According to Spearman's rho correlations analysis, FAMACHA scores (Kilakarsal: $-0.802^{*}$ and Vembur: $-0.893^{* *}$ ) and FEC (Kilakarsal: $-0.811^{* *}$ and Vembur: $-0.920^{* *}$ ) had negative associations with PCV which are highly significant $(p<0.01)$ and the FAMACHA scores exhibited a highly significant positive association with FEC with values of $0.957^{* *}$ and $0.954^{* *}$ in Kilakarsal and Vembur sheep, respectively. It is concluded that the FAMACHA score, FEC, PCV are the best indicator traits for gastrointestinal nematode infection, especially Haemonchus contortus is major disease causing pathogen. The correlation analysis of indicator traits will help in selection of genetically resistant animals against gastrointestinal infection.

KEYWORDS: FAMACHA, correlation, FEC, gastrointestinal nematode, kilakarsal, PCV, vembur

Citation (VANCOUVER): Selvam, Genetic Parameter Analysis of Indicator Traits of Gastrointestinal Nematode Infection in Sheep Breeds. International Journal of Bio-resource and Stress Management, 2022; 13(1), 17-21. HTTPS://DOI.ORG/10.23910/1.2022.2657.

Copyright: @ 2022 Selvam. This is an open access article that permits unrestricted use, distribution and reproduction in any medium after the author(s) and source are credited.

Data Availability Statement: Legal restrictions are imposed on the public sharing of raw data. However, authors have full right to transfer or share the data in raw form upon request subject to either meeting the conditions of the original consents and the original research study. Further, access of data needs to meet whether the user complies with the ethical and legal obligations as data controllers to allow for secondary use of the data outside of the original study.

Conflict of interests: The authors have declared that no conflict of interest exists.

RECEIVED on $05^{\text {th }}$ October 2021 RECEIVED in revised form on $10^{\text {th }}$ January 2022 ACCEPTED in final form on $20^{\text {th }}$ January 2022 PUBLISHED on $25^{\text {th }}$ January 2022 


\section{INTRODUCTION}

$\mathrm{I}^{\mathrm{n}}$ n sheep, Haemonchus contortus is the most economically significant gastrointestinal nematode due to the severity of the parasitism, high mortality and the emerging anthelmintic resistance (Goel et al., 2020; Muhammad et al., 2021). It has a small tooth that lacerates the abomasum wall and it feeds on the blood that is released which result in anemia. The Parasite cause major loss to farmers by reducing the animal production, weight, conception rate, altered carcass composition and clinical effects viz. roughness of coat, edema, diarrhoea (Praveen et al., 2018). Controlling of gastrointestinal nematode requires an integrated control strategy which combines chemical and nonchemical approaches (Qokweni et al., 2021). The integrated control strategy includes management practices that minimize infection, strategic deworming of infected and highly susceptible individuals, known as targeted selective treatment, and the genetic selection of lines or breeds of hosts to increase host resistance and/ or resilience to parasites (Pereiraa et al., 2016). Rapid diagnosis, strategic prevention, and pasture management will facilitate the control of gastrointestinal nematode infection (Peter, 2006; Ngere et al., 2018).

The clinical diagnosis of haemonchosis is based mostly on the detection of anemia through faecal worm egg counts (FEC), packed cell volume (PCV) and the FAffa MAlan CHArt (FAMACHA) conjunctival-colour index (Beh and Maddox, 1996; Hailey et al., 2020). Both FEC and $\mathrm{PCV}$ are traits of value, as FEC is an indirect measure of resistance and PCV is an indicator of resilience, i.e. the ability of the animal to withstand the effects of infection. In ideal circumstances, it would be desirable to select for both decreased FEC and increased PCV (Dominik, 2005).

In haemonchosis, anemia is the principle clinical problem and the mucous membrane pallor is one of the easiest ways to diagnose. The FAMACHA system uses a 5-point scale to measure ocular mucous membrane color, which correlates with packed cell volume. The FAMACHA system was developed to estimate the level of anemia in sheep and goats associated with Haemonchus contortus infection. It is a tool that matches the color of the eye mucous membranes of small ruminants with a laminated color chart showing 5 color categories that correspond to different levels of anemia. Category 1 represents "not anemic", with category 5 representing "severely anemic". The FAMACHAC system is an important tool in identifying and selectively deworming sheep. It can also aid in selective breeding decisions by identifying those animals that are most susceptible to Haemonchus contortus infection (Burke et al., 2007). The successful use of FAMACHA system of clinical evaluation of anaemia associated with haemonchosis has facilitated the adoption of targeted selective treatment which is regarded as an alternate approach to reduce anthelmintic resistance in sheep (Thomas and Syamala, 2016; Cintra et al., 2020). The FAMACHA system is based on the principle of the correlation between the eye mucous colour and the PCV values and identifying animals that are able to withstand infections by Haemonchus contortus. Using this approach one would allow the survival of an anthelmintic sensitive parasite population to persist on the environment, without being exposed to anthelmintic treatment, reducing the selection pressure towards resistance (Vinicius et al., 2012; Cintra et al., 2018)

Knowledge on correlation among economic indicator traits of gastrointestinal nematode infection is essential for selection of sheep for disease resistance. This study was undertaken with an aim to study the indicator traits of gastrointestinal nematode infection viz., FAMACHA score, FEC and PCV in Kilakarsal and Vembur breeds of sheep and further to estimate the correlation among the traits.

\section{MATERIALS AND METHODS}

7 his study was carried out in Kilakarsal breed of sheep maintained at Livestock Farm Complex, Veterinary College and Research Institute, Tirunelveli and Sheep farm, Sattur and Vembur breed of sheep maintained at Livestock Farm Complex, Veterinary College and Research Institute, Tirunelveli and District livestock farm, Abishegappatti, Tirunelveli during 2014-16. A total of 100 sheep, 50 of each breeds, aged from 6 to 18 months and both male and female were randomly selected for this study. All the animals were maintained under semi-intensive system of management and normal natural grazing conditions and were dewormed routinely once in three months with different rotational anthelmintics as per the standard procedure. The faecal egg count, packed cell volume and FAMACHA score were recorded as per the standard protocol. The faecal egg counting was conducted using the modified McMaster technique. Faecal cultures were prepared from pooled faecal samples taken from a random sample to define the species composition of the nematodes that infected the flock. Fresh blood samples were collected on the day of faecal sampling for measuring packed cell volume. PCV was estimated by the microhaematocrit centrifuge method (Maff, 1977). Data on FEC, PCV and FAMACHA score were used for subsequent analyses. The data were analysed using a mixed model least-squares analysis for fitting constants (Preston and Allonby, 1978). The relationship among FEC, PCV and FAMACHA score were estimated by Pearson correlation coefficient and Spearman's Rank-Order correlation coefficient methods 
using SPSS statistics tool.Before performing correlation coefficient, a scatter plot is used for bivariate data which is a visual presentation that gives information about the extent of the relationship between the two variables.

\section{RESULTS AND DISCUSSION}

$\mathrm{T}$ he overall least-squares means for FAMACHA score, FEC and PCV of Kilakarsal and Vembur sheep are presented in Table 1. In Kilakarsal and Vembur sheep, the overall least-squares mean for FAMACHA scores were $2.88 \pm 1.144$ and $2.9 \pm 0.151$; FEC were $792 \pm 121.448$ and $767.0 \pm 100.576$; PCV were $26.38 \pm 0.199$ and $26.14 \pm 0.189$, respectively.

Table 1: Least-squares means FAMACHA scores, FEC and PCV of Kilakarsal and Vembur sheep

\begin{tabular}{lcc}
\hline & Kilakarsal & Vembur \\
\hline FAMACHA & $2.88 \pm 1.144$ & $2.9 \pm 0.151$ \\
FEC & $792 \pm 121.448$ & $767.0 \pm 100.576$ \\
PCV & $26.38 \pm 0.199$ & $26.14 \pm 0.189$ \\
\hline
\end{tabular}

The Figures 1 and 2 shows the scatter plot of bivariate data of various combinations of FAMACHA score, FEC and PCV in Kilakarsal and Vembur sheep. The figure 1 and 2 showed the uphill pattern which indicates a positive relationship between FAMACHA scores and FEC. The downhill pattern indicates a negative relationship between FAMACHA score and PCVand betweenFEC and PCV in Kilakarsal and Vembur sheep, respectively. These results confirm that higher FAMACHA scores were associated with higher FEC.

The Pearson Correlations of FAMACHA scores, FEC and PCV in Kilakarsal and Vembur Sheep are presented in Table 2 and 3, respectively. From this result it has been observed that there is highly significant $(\mathrm{P}<0.01)$ positive correlation between FAMACHA scores and FEC in Kilakarsal $\left(0.835^{\circ *}\right)$ and Vembur $\left(0.863^{* *}\right)$ sheep. But, PCV is negatively correlated with FAMACHA scores (Kilakarsal: $-0.843^{* *}$ and Vembur: $-0.883^{* *}$ )and FEC(Kilakarsal: $-0.874^{* *}$ and Vembur: $-0.924^{* * *}$ ), which is also highly significant $(p<0.01)$. The Faecal egg culture results showed that the sheep were infected mostly with blood sucking Haemonchus contortus which is substantiated by the higher FAMACHA scores and FEC was associated with lower PCV in this study.

Spearman's rho Correlations analysis: The comparable kind of result is also observed in the Spearman's rho Correlations analysis (Table 2 and 3). Where the FAMACHA scores (Kilakarsal: $-0.802^{* *}$ and Vembur: $-0.893^{* *}$ ) and FEC (Kilakarsal: $-0.811^{* *}$ and Vembur:

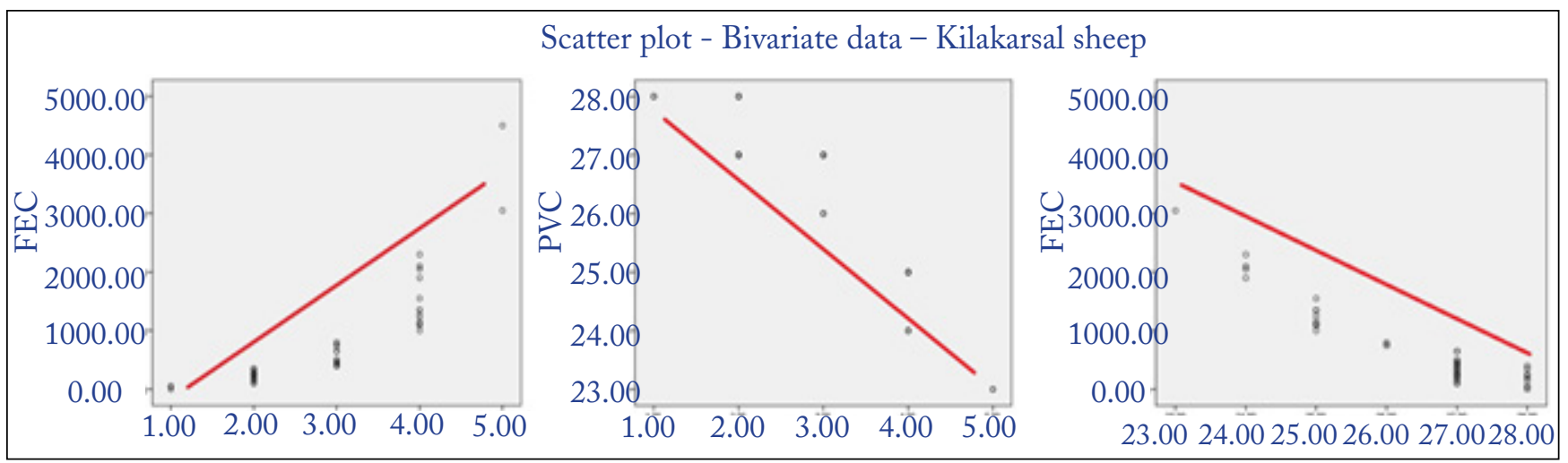

Figure 1: Scatter plot - Bivariate data - Kilakarsal sheep

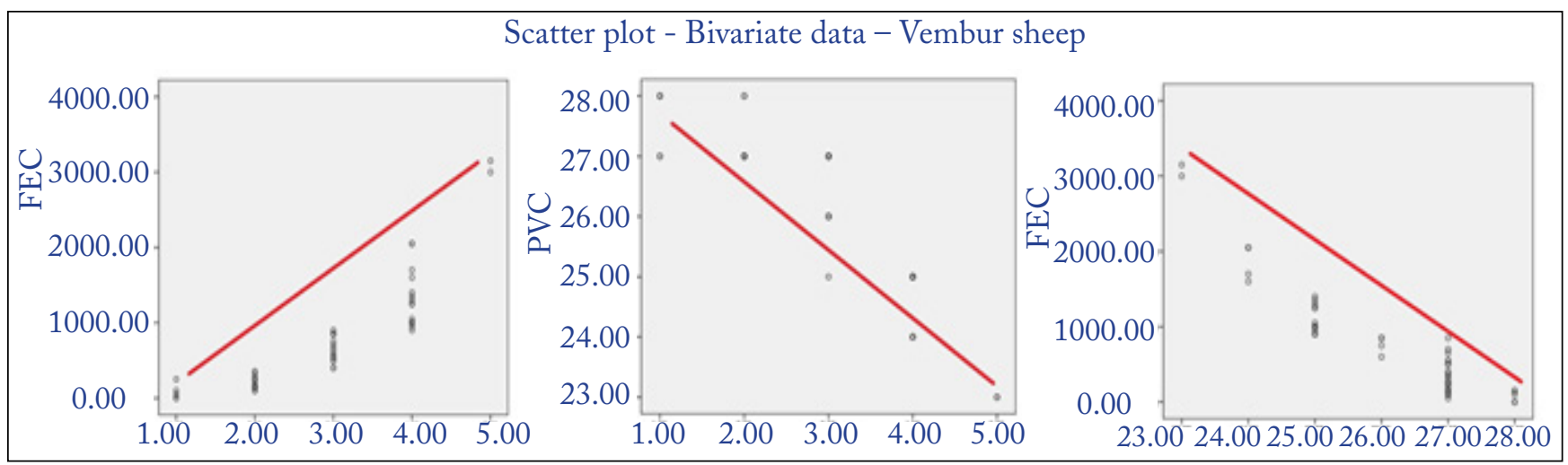

Figure 2: Scatter plot - Bivariate data - Vembur sheep 
Table 2: Pearson and spearman rho correlations of FAMACHA scores, FEC and PCV of kilakarsal sheep

\begin{tabular}{lcccccc}
\hline & \multicolumn{3}{c}{ Pearson correlation coefficient } & \multicolumn{2}{c}{ Spearman rho correlation coefficient } \\
\cline { 2 - 6 } & FAMACHA & FEC & PCV & FAMACHA & FEC & PCV \\
\hline FAMACHA & 1 & $0.835^{* *}$ & $-0.843^{* *}$ & 1 & $0.957^{* * *}$ & $-0.802^{* *}$ \\
FEC & $0.835^{* *}$ & 1 & $-0.874^{* *}$ & $0.957^{* * *}$ & 1 & $-0.811^{* * *}$ \\
PCV & $-0.843^{* *}$ & $-0.874^{* *}$ & 1 & $-0.802^{* * *}$ & $-0.811^{* *}$ & 1 \\
\hline
\end{tabular}

Table 3: Pearson and spearman rho correlations of FAMACHA scores, FEC and PCV of vembur sheep

\begin{tabular}{lcccccc}
\hline & \multicolumn{3}{c}{ Pearson correlation coefficient } & \multicolumn{2}{c}{ Spearman rho correlation coefficient } \\
\cline { 2 - 6 } & FAMACHA & FEC & PCV & FAMACHA & FEC & PCV \\
\hline FAMACHA & 1 & $0.863^{* * *}$ & $-0.883^{* *}$ & 1 & $0.954^{* * *}$ & $-0.893^{* * *}$ \\
FEC & $0.863^{* * *}$ & 1 & $-0.924^{* *}$ & $0.954^{* * *}$ & 1 & $-0.920^{* * *}$ \\
PCV & $-0.883^{* * *}$ & $-0.924^{* *}$ & 1 & $-0.893^{* *}$ & $-0.920^{* *}$ & 1 \\
\hline
\end{tabular}

$\left.-0.920^{* *}\right)$ had negative associations with PCV which are highly significant $(p<0.01)$. The FAMACHA scores exhibited a highly significant positive association with FEC with values of $0.957^{* *}$ and $0.954^{* *}$ in Kilakarsal and Vembur sheep, respectively.

In the present study, the faecal egg culture results showed that the sheep were infected mostly with Haemonchus contortus. Mugambi et al. (2005) stated that the Haemonchus contortus often lead to the lower PCV values and other haematological disturbances and it is attributed to the loss of blood through gastrointestinal tract by the injuries caused by this parasite. In this study the PCV is negatively correlated to FEC and FAMACHA scores, whereas, FEC is positively correlated with FAMACHA scores. Similar findings were reported in various studies. Guash et al. (2015) reported that a highly significant negative correlations between PCV and FAMACHA score and FEC and positive correlations observed between FAMACHA score and FEC. Burke et al. (2007) reported a highly significant exponential increase in mean FEC with increasing FAMACHA scores in sheep and a correlation of 0.44 between FAMACHA score and FEC. Notter et al. (2017) concluded that a higher FAMACHA scores were associated with higher FEC in Katahdin lambs. Hailey et al. (2020) also reported that the FAMACHA score was highly related to FEC in sheep. In Kilakarsal sheep, Selvam and Venkataramanan (2018) recorded significant negative correlation in FEC with PCV $(-0.705)$ and In Vembur sheep. The negative correlation between FEC and $\mathrm{PCV}$ was reported in fine-wool Merino lambs (Woolaston and Piper, 1996) in Polish Long Wool sheep (Greer et al., 2009 ), in Scottish Blackface lambs (Bouix et al., 1998). Adamu et al. (2020) state that the FAMACHAsystem is suitable indicator of anaemia and may provide an additional part of integrated anthelmintic control of sheep, and its use may reduce chances of anthelmintic resistance development. The result implies that when FEC and FAMACHA score increases, $\mathrm{PCV}$ reduces. The correlation of FAMACHA scores with FEC and PCV may assist in field diagnosing animals with gastrointestinal nematode infection and aid in treating the animals and also in selection of genetically resistant animals against gastrointestinal nematode infection.

\section{CONCLUSION}

Tn this study the FAMACHA score was highly 1 significantly positively correlated with the FEC and negatively correlated with PCV in Kilakarsal and Vembur sheep. These data indicate that the FAMACHA score, FEC, PCV are the best indicator traits for gastrointestinal nematode infection. Also this analysis will help in selection of genetically resistant animals against gastrointestinal infection. In future this study can be further extended with genomic studies to identify the markers for the genetic resistance to gastrointestinal nematode infection.

\section{ACKNOWLEDGEMENT}

$\mathrm{T}$ he authors are very much grateful to the Tamil Nadu Veterinary and Animal Sciences University, Chennai -600051 for providing necessary facilities for conducting the study.

\section{REFERENCE}

Adamu, M., Dzever, P., Ikurior, S., Ode, S., Williams, J., 2020. Validation of the FAMACHA ${ }^{\odot}$ system for detecting anaemia and helminthosis in West African Dwarf sheep in Makurdi, Benue State, Nigeria. Comparative Clinical Pathology 29, 965970.

Beh, K.J., Maddox, J.F., 1996. Prospects for development of genetic markers for resistance to gastrointestinal parasite infection in sheep. International Journal of Parasitology 26, 879-897. 
Bouix, J., Krupinski, J., Rzepecki, R., Nowosad, B., Skrzyzala, I., Roborzynski, M., FudalewiczNiemczyk, W., Skalska, M., Malczewski, A., Gruner, L.,1998. Genetic resistance to gastrointestinal nematode parasites in Polish long wool sheep. International Journal of Parasitology 28, 1797-1804.

Burke, J.M., Kaplan, R.M., Miller, J.E., Terrill, T.H., Getz, W.R., Mobini, S., Valencia, E., Williams, M.J., Williamson, L.H., Vatta, A.F., 2007. Accuracy of the $\mathrm{FAMACHA}^{\odot}$ system for on-farm use by sheep and goat producers in the southeastern United States. Veterinary Parasitology 147(1-2), 89-95.

Cintra, M.C.R., Ollhoff, R.D., Weber, S.H., Sotomaior, C.S., 2019. Is the FAMACHA ${ }^{\odot}$ system always the best criterion for targeted selective treatment for the control of haemonchosis in growing lambs? Veterinary Parasitology 266, 67-72.

Cintra, M.C.R., Ollhoff, R.D., Sotomaior, C.S., 2018. Sensitivity and specificity of the FAMACHA $^{\odot}$ system in growing lambs. Veterinary Parasitology 251, 106-111.

Dominik, S., 2005. Quantitative trait loci for internal nematode resistance in sheep: a review. Genetics Selection and Evolution 37, S83-S96.

Goel, V., Singla, L.D., Choudhury, D., 2020. Cuminaldehyde induces oxidative stress-mediated physical damage and death of Haemonchus contortus. Biomedicine \& Pharmacotherapy 130, 11041

Greer, A.W., Kenyon, F., Bartley, D.J., 2009. Development and field evaluation of a decision support model for anthelmintic treatments as part of a targeted selective treatment (TST) regime in lambs. Veterinary Parasitology 164, 12-20.

Guash, A., Tilaye, D., Amene, F., Teshale, T., 2015. Sheep Infection by haemonchus species: effect on haematocrit and evaluation of the FAMACHAC method in Arsi Negele district, Oromia, Ethiopia. Animal and Veterinary Sciences 3(2), 74-79.

Hailey, R.G., Anne, M.Z., Lee, W., Scott, P.G., Heather, L.B., 2020. Evaluating the relationship between fecal egg count, FAMACHA score, and weight in dewormed and non-dewormed Katahdin rams during a parasite challenge. Translational Animal Science 4, 178.

Maff, 1977. Manual of veterinary parasitology laboratory technique. technical bulletin No. 18. Her Majesty's Stationery Office, Ministry of Agriculture, Fisheries and Food, London. pp. 160.

Mugambi,J.M.,Audho,J.O., Baker, R.L.,2005.Evaluation of the phenotypic performance of a red Maasai and Dorper double backcross resource population: natural pasture challenge with gastrointestinal nematode parasites. Small Ruminant Research 56, 239-251.

Muhammad, N., Zahid, I., Nabila, R., 2021. Ovine haemonchosis: a review. Tropical Animal Health Production 53, 19.

Ngere, L., Burke, J.M., Morgan, J.L.M., Miller, J.E., Notter, D.R., 2018. Genetic parameters for fecal egg counts and their relationship with body weights in Katahdin lambs. Journal of Animal Science 96, 1590-1599

Notter, D.R., Burke, J.M., Miller, J.E., Morgan, J.L.M., 2017. Association between FAMACHA scores and fecal egg counts in Katahdin lambs. Journal Animal Science 95(3), 1118-1123.

Pereiraa, J.F.S., Mendesa, J.B., Jongb, G.D., Maiaa, D., Teixeirab, V.N., Passerinob, A.S., Garzac, J.J., Sotomaior, C.S., 2016. FAMACHA ${ }^{\odot}$ scores history of sheep characterized as resistant/resilient or susceptible to $H$. contortus in artificial infection challenge. Veterinary Parasitology 218, 102-105.

Peter, J.W., 2006. Sustainable nematode parasite control strategies for ruminant livestock by grazing management and biological control. Animal Feed Science and Technology 126(3), 277-289.

Praveen, P., Abhishek, G., Poonam, C., Pilania, P.K., 2018. Studies on gastrointestinal nematodosis and associated risk factors in dairy animals of arid western plains of rajasthan. International Journal of Bioresource and Stress Management 9(6), 718-722.

Preston, J.M., Allonby, E.W., 1978. The influence of breed on the susceptibility of sheep and goats to a single experimental infection with Haemonchus contortus. Veterinary Record 103, 509-512.

Qokweni, L., Chimonyo, M., Marufu, M.C., 2021. Differences in burden of gastrointestinal nematode infestations in indigenous does foraging in grassland and forestland vegetation types. Tropical Animal Health Production 53, 455.

Selvam, R., Venkataramanan, R., 2018. Genetic parameter estimates for phenotypic indicator traits of resistance to gastrointestinal nematode infection in kilakarsal sheep. International Archive of Applied Sciences and Technology 9(3), 46-50.

Thomas, M., Syamala, K., 2016. Efficacy of FAMACHA ${ }^{\odot}$ eye colour chart in the assessment of parasitic load and anaemia in goats of humid tropics. Indian Veterinary Journal 93(2), 54-56.

Vinicius, L.R.V., Thais, F.F., Emanuel, F.L., Ana Celia, R.A., Marcelo, B.M., Sergio, S.A., 2012. FAMACHAC method as an auxiliary strategy in the control of gastrointestinal helminthiasis of dairy goats under semiarid conditions of Northeastern Brazil. Veterinary Parasitology 190, 281-284.

Woolaston, R.R., Piper, L.R., 1996. Selection of merino sheep for resistance to Haemonchus contortus: genetic variation. Animal Science 62, 451-460. 